\title{
Identification of Proteins in Cell-Free Extracts Using Liquid Chromatography-Electrospray Ionization Mass Spectrometry
}

BioTechniques 28:156-160 (January 2000)

\author{
Joseph J. Dalluge and Prasad \\ Reddy \\ National Institute of Standards \\ and Technology, Gaithersburg, \\ MD, USA
}

\section{INTRODUCTION}

Expression of recombinant proteins in bacterial and eukaryotic hosts has become a routine practice in biomolecular research laboratories (8). Protein expression is most often monitored using SDS polyacrylamide gel electrophoresis (PAGE) (7). The identification of proteins using this labor-intensive method is confounded by low mass resolution and accuracy, and the inability to detect posttranslational modifications.

The limitations associated with SDS-PAGE analysis of proteins have been overcome in recent years through the development of mass spectrometric techniques for the characterization of biomolecules, specifically with the advent of techniques using matrix-assisted laser desorption ionization (MALDI) $(10,11)$ and electrospray ionization (ESI) (6) mass spectrometry (MS). In addition, the direct determination of proteins using mass spectrometry in complex biologically derived mixtures without extensive sample purification has also been described $(1-3,5)$. Beavis and Chait first reported the use of MALDI-MS for the analysis of protein mixtures in bovine milk and the high density lipoprotein fraction of human plasma (1). Since then, several MALDI-MS methods for monitoring and profiling protein expression in bacterial cells have appeared in the literature $(2,3,5)$. While these techniques represent a marked improvement over laborintensive gel preparation and analysis, sample preparation for the removal of excess salts and impurities $(1-3,5,9,17)$ before analysis by MALDI-MS can represent a challenge to the non-expert.
Here, we report a simple and rapid method using directly combined liquid chromatography (LC)-ESIMS for the direct identification of phosphoenolpyruvate-sugar phosphotransferase system (PTS) recombinant proteins in bacterial cell-free extracts. This method overcomes the above noted limitation by adding a second dimension to the determination of proteins in complex mixtures by mass spectrometry, and represents a practical complement to analogous MALDI-MS techniques for determination of proteins in complex mixtures.

\section{MATERIALS AND METHODS}

\section{Chemicals}

Bacto-tryptone and yeast extract were purchased from Difco (Detroit, MI, USA). Phosphoenolpyruvate and trifluoroacetic acid (TFA) were obtained from Sigma (St. Louis, MO, USA). HPLC-grade acetonitrile (ACN) was purchased from Baker-Mallinkrodt (Phillipsburg, NJ, USA). HPLC-grade water, purified using a Milli- ${ }^{\circledR}$ purification system (Millipore, Bedford, MA, USA), was used to prepare all solutions. All other chemicals were of analytical grade.

\section{Escherichia coli Strains and Plasmids}

E. coli strain MZ1 ( $\lambda$ cI857 lysogen) (18) was kindly provided by Dr. Donald Court of the National Cancer Institute, Frederick, MD, USA. A PTS deletion $E$. coli strain (DG40), the plasmid 
pDS20 carrying $p t s \mathrm{H}$ and ptsI genes and the plasmid pDS45 carrying the $\mathrm{crr}$ gene (16) were kindly provided by Dr. Saul Roseman of The Johns Hopkins University, Baltimore, MD, USA. Cloning of ptsI into the pRE1 expression vector (15), pts $\mathrm{H}$ into the $\mathrm{pKC} 30$ expression vector (13) and $\mathrm{crr}$ into the pRE1 expression vector (14) has been described elsewhere.

\section{Expression of PTS Proteins}

Strain MZ1 carrying the pRE1 expression vector harboring $p t s I$ or the $c r r$ gene was grown in $100 \mathrm{~mL} \mathrm{LB}$ medium containing ampicillin $(50 \mu \mathrm{g} / \mathrm{mL})$ at $32^{\circ} \mathrm{C}$ to an $\mathrm{A}_{650}$ of 0.4 . A $40 \mathrm{~mL}$ aliquot of this culture was saved for estimating the uninduced level of the PTS protein(s). The remainder of the culture was diluted with an equal volume of fresh LB equilibrated to $60^{\circ} \mathrm{C}$ and immediately shifted to a $42^{\circ} \mathrm{C}$ waterbath shaker for $2 \mathrm{~h}$ to induce gene expression. Cells were collected by centrifugation at $5000 \mathrm{rpm}$ (Beckman J2-M1, Palo Alto, CA, USA) for $15 \mathrm{~min}$, washed with $25 \mathrm{mmol} / \mathrm{L}$ Tris- $\mathrm{HCl}, \mathrm{pH}$ 7.5 , and suspended in $2 \mathrm{~mL}$ of 50 $\mathrm{mmol} / \mathrm{L}$ Tris-HCl, $\mathrm{pH} 7.5$, containing 1 $\mathrm{mmol} / \mathrm{L}$ EDTA and $0.2 \mathrm{mmol} / \mathrm{L}$ dithiothreitol (DTT), pH 7.5. Cells were broken by passage through a French pressure cell at $69 \mathrm{MPa}(10000 \mathrm{psi})$. Cell lysates were centrifuged at $14000 \mathrm{rpm}$ in an Eppendorf ${ }^{\circledR}$ microcentifuge (Brinkmann Instruments, Westbury, NY, USA) for $10 \mathrm{~min}$ before direct analysis by LC-MS. This sample preparation step was effective in removing from the samples large particulates that might obstruct the LC column. The concentration of protein in the lysate

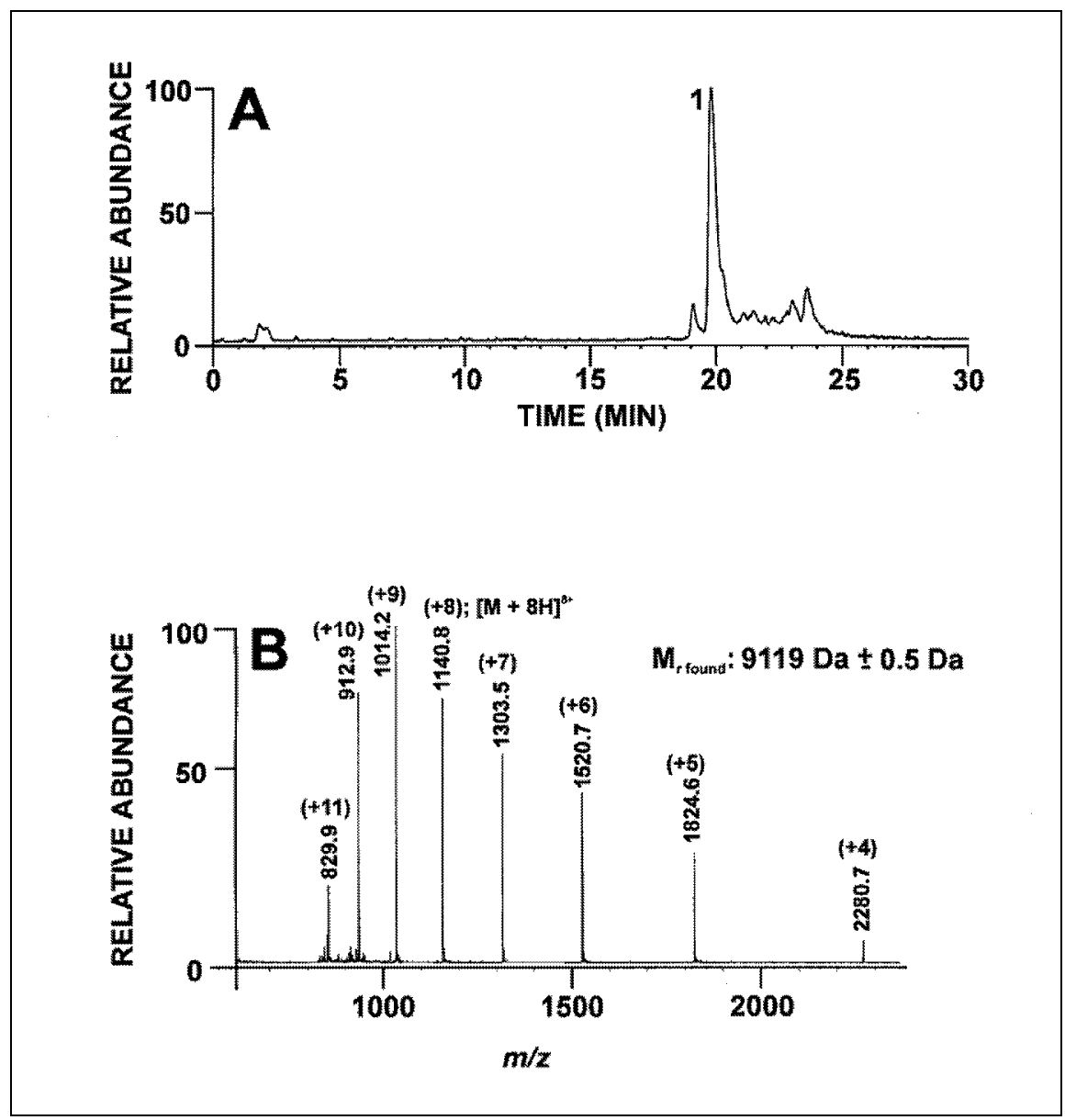

Figure 1. Determination of $E$. coli PTS protein HPr in a crude cell-free extract. (A) Total ion chromatogram, LC gradient elution System 1; (B) Average mass spectrum calculated for peak 1 . The chargestate corresponding to each $\mathrm{m} / \mathrm{z}$ value of the multiply charged protein is indicated in parentheses. MS parameters are described in Materials and Methods. $(\sim 12 \mathrm{mg} / \mathrm{mL})$ was determined as described previously (12).

\section{Phosphorylation of PTS Proteins}

The phosphoenolpyruvate (PEP)dependent phosphorylation of Protein IIAGlc was achieved in a $250 \mu \mathrm{L}$ reaction mixture containing $1 \mathrm{mmol} / \mathrm{L} \mathrm{PEP}$, $10 \mathrm{mmol} / \mathrm{L} \mathrm{MgCl}_{2}, 50 \mathrm{mmol} / \mathrm{L}$ Tris$\mathrm{HCl}, \mathrm{pH} 7.5,0.2 \mathrm{mmol} / \mathrm{L}$ dithiothreitol and $5 \mathrm{mg}$ of protein from the cell-free extract enriched with Protein IIAGlc and catalytic quantities of HPr and Enzyme I encoded by the E. coli MZ1 chromosome.

\section{Directly Combined LC-ESIMS}

Analysis of proteins in cell-free extracts from $E$. coli was carried out with a Hewlett Packard Series 1100 LC/ MSD instrument (Wilmington, DE, USA) consisting of an HP 1100 series liquid chromatograph with a variable wavelength UV absorbance monitor placed in series between the chromatograph and the electrospray-single quadrupole mass spectrometer. LC separations were made using a $2.1 \times 150$ mm Zorbax 300SB-C8 reversed-phase chromatography column (Mac Mod Analytical, Chadds Ford, PA, USA) thermostatted at $30^{\circ} \mathrm{C}$. The LC mobile phase consisted of (A) water containing a volume fraction of $0.05 \%$ trifluoroacetic acid (TFA); (B) ACN containing a volume fraction of $0.05 \%$ TFA. The PTS proteins HPr and Enzyme I were eluted using the following gradient elution system (System 1) at a flow rate of $0.250 \mathrm{~mL} / \mathrm{min}$ : isocratic at $15 \% \mathrm{~B}, 0-5$ min, linear from $15 \%-80 \% \mathrm{~B}, 5-30$ min. A second gradient elution system (System 2), developed to optimize the separation of the native and phosphorylated forms of PTS protein IIAGlc, was isocratic at 35\% B, 0-3 min, and linear from $35 \%$ to $65 \% \mathrm{~B}, 3-30 \mathrm{~min}$. Electrospray mass spectra were acquired over the mass/charge range 700-2500 every $1.5 \mathrm{~s}$ during the chromatographic separations. The following instrumental parameters were used for MS detection: gain, 3; fragmentor voltage, 120 $\mathrm{V}$; threshold, 100; step size, 0.15; drying gas, $12 \mathrm{~L} / \mathrm{min}$; nebulizer pressure, 25 psi; drying gas temperature, $350^{\circ} \mathrm{C}$; capillary voltage, $4000 \mathrm{~V}$. 


\section{RESULTS AND DISCUSSION}

Our success has been limited in preparing contaminated protein samples (e.g., those found in complex matrixes such as bacterial cell extracts) for MALDI-MS analysis using the variety of on-probe sample cleanup protocols reported in the literature $(1-3,5,9,17)$. The aim of this study was therefore to establish the usefulness of directly combined LC-MS for the determination of proteins in bacterial cell-free extracts. The described technique requires no sample preparation or pre-purification other than the isolation of cell-free extracts. It uses a benchtop, commercially available LC-MS instrument that is easily operated regardless of user experience. The results of this investigation further demonstrate the power that this simple technique has in the biomolecular research laboratory, namely immediate verification of protein expression in a cell culture, concurrent with a preliminary structural characterization of that protein.

\section{Identification of Recombinantly Expressed Sugar Transport Proteins in Crude Cell-Free Extracts of $E$. coli}

The usefulness of LC-ESIMS for the identification of overexpressed proteins in E. coli cell-free extracts was first demonstrated for the PTS protein HPr. The results of this experiment are illustrated in Figure 1. Figure 1A shows the total ion chromatogram for the LCMS analysis of $4 \mu \mathrm{L}$ of a cell-free extract with a major peak eluting at 20 min. UV absorbance at $215 \mathrm{~nm}$ was also monitored over the course of the LC gradient elution to corroborate the MS data (UV absorbance chromatogram not shown). The assignment of the major component as the PTS protein $\mathrm{HPr}$ was made by averaging the mass spectra collected every $1.5 \mathrm{~s}$ under the chromatographic peak. The result is the average mass spectrum illustrated in Figure 1B. Each peak in Figure 1B results from protein molecules of the same mass with different numbers of protons attached (individual charge states are indicated in Figure 1B) and therefore different mass-tocharge $(\mathrm{m} / \mathrm{z})$ ratios.

The data system of the mass spec- trometer calculates the molecular mass of the protein based on knowledge of the charge state and corresponding $\mathrm{m} / \mathrm{z}$ value for each peak in the spectrum. The mathematical conversion of this envelope of $\mathrm{m} / \mathrm{z}$ values to molecular mass is termed deconvolution. Deconvolution of the spectrum illustrated in Figure 1B identifies a protein of molecular weight $9119.5 \pm 0.5 \mathrm{Da}$. The calculated molecular weight of HPr as defined by its predicted amino acid sequence (16) is $9119.37 \mathrm{Da}$. This represents a single-run mass measurement error of $<0.001 \%$.

So as not to overstate the actual capabilities of the instrument used in this study, it should be noted that more typical mass accuracy values for this type of measurement are approximately $0.01 \%$. This value can be compared with molecular weight accuracy values using SDS-PAGE, which normally range from $5 \%-10 \%$ provided there are no posttranslational modifications that affect protein migration under the influ- ence of an electric field. Considering this and the data presented in Figure 1, the advantage of this method for providing immediate feedback regarding the success of HPr expression, as well as providing a preliminary structural characterization of the protein, is obvious. In addition, no problems (e.g., column obstruction and sample carryover) have been encountered with regard to repeated use of this technique for the analysis of cell-free extracts.

To determine the mass range over which this technique would be routinely useful, two additional PTS proteins, Protein IIAGlc and Enzyme I, were expressed in $E$. coli followed by their identification using LC-ESIMS. Figure 2 shows these results. Figures $2 \mathrm{~A}$ and 2B show total ion chromatograms for the determinations of Protein IIAGlc and Enzyme I, respectively. The insets display the average mass spectra collected under the labeled chromatographic peaks. The molecular weight $\left(M_{\mathrm{r}}\right)$ determined for the major compo-

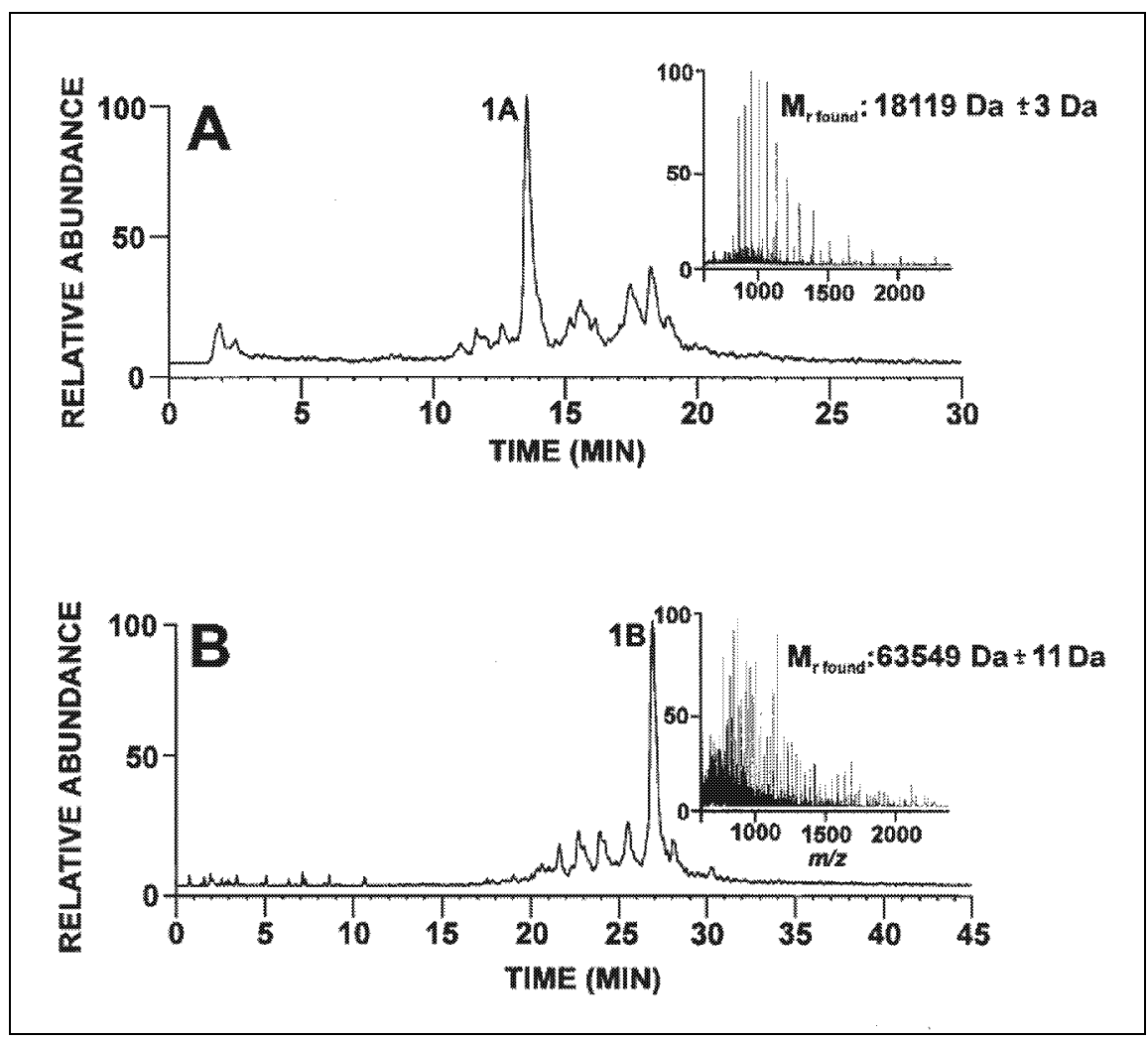

Figure 2. Determination of $\boldsymbol{E}$. coli PTS proteins in crude cell-free extracts. (A) Total ion chromatogram, LC gradient elution System 2, for the determination of Protein IIAGlc and average mass spectrum (inset) calculated for peak 1A; (B) Total ion chromatogram, LC gradient elution System 1, for the determination of Enzyme I and average mass spectrum (inset) calculated for peak 1B. MS parameters are described in Materials and Methods. 
nent in Figure 2A is $18119 \pm 3 \mathrm{Da}$. The theoretical $M_{\mathrm{r}}$ of Protein IIAGlc based on its amino acid sequence (16) is $18251 \mathrm{Da}$. The difference between the experimentally determined $M_{\mathrm{r}}$ and the theoretical value, $132 \mathrm{Da}$, indicates the loss of a methionine residue (mass, 131.21 Da) from Protein IIAGlc.

It would be reasonable to hypothesize that the $\mathrm{N}$-terminal methionine residue of Protein IIAGlc has been removed, as this represents a common posttranslational modification. However, identification of sites of posttranslational modification cannot be made based on mass spectra of intact proteins alone, and any such claim would have to be verified by $\mathrm{N}$-terminal sequencing or peptide mapping of the protein. The $M_{\mathrm{r}}$ determined for the major compo-

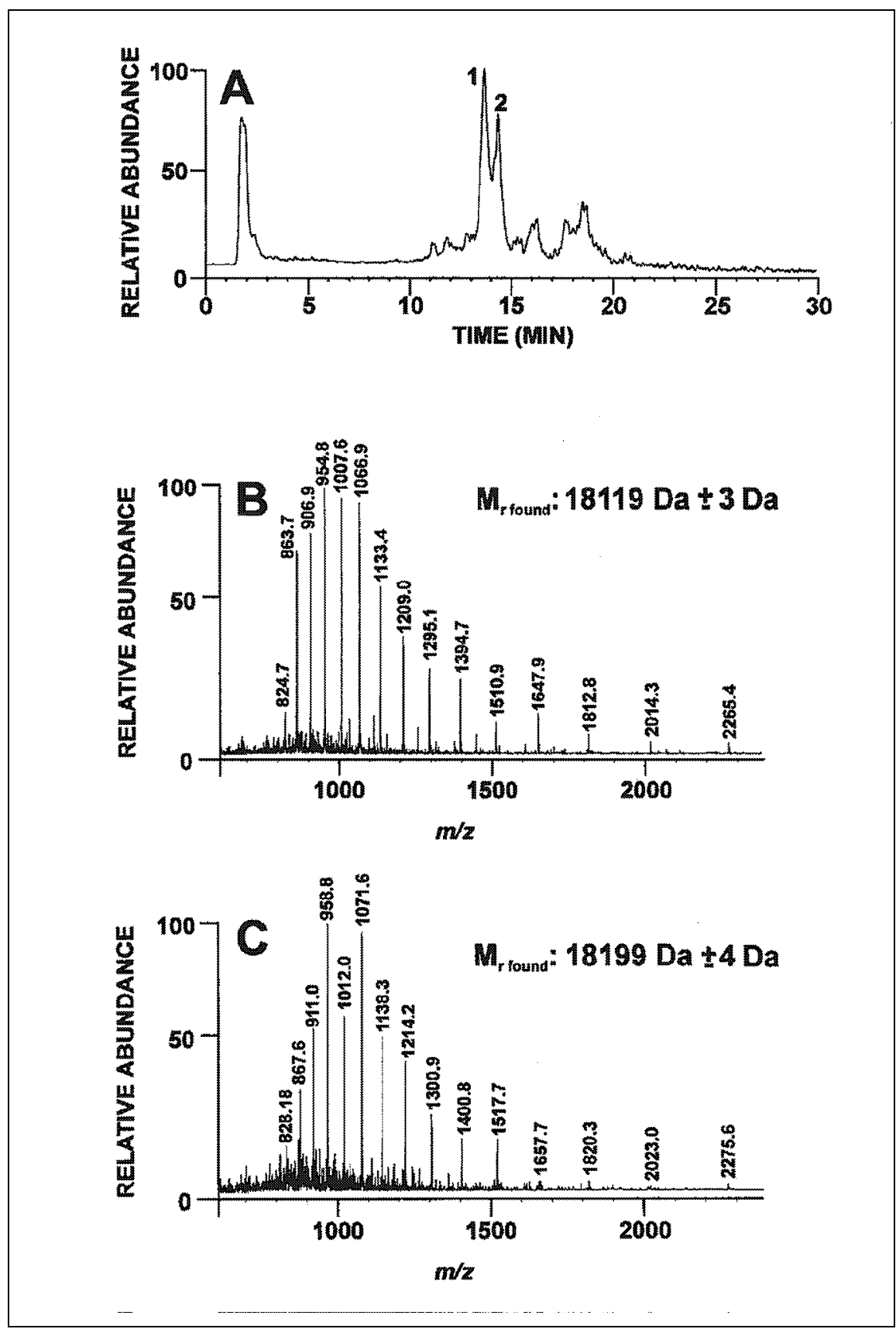

Figure 3. Identification of phosphorylation of $\boldsymbol{E}$. coli PTS Protein IIAGlc. (A) Total ion chromatogram, LC gradient elution System 2; (B) Average mass spectrum calculated for peak 1; (C) Average mass spectrum calculated for peak 2. MS parameters are described in Materials and Methods. 
nent in Figure 2B is $63549 \pm 11 \mathrm{Da}$. The predicted molecular weight of $E$. coli Enzyme I based on its amino acid composition (16) is $63561 \mathrm{Da}$. Therefore the experimentally determined value of 63549 Da represents a mass accuracy of $0.02 \%$ for Enzyme I.

Two conclusions about the LC-ESIMS technique can be made in consideration of these results. First, the mass range over which proteins can be routinely measured using LC-ESIMS is at least $10-65 \mathrm{kDa}$ (no larger proteins were tested). Second, this method, unlike more traditional biochemical methods, is capable of directly detecting small chemical modifications such as the loss of the methionine residue from Protein IIAGlc.

To demonstrate further the facility of this technique in rapidly identifying chemical modifications in proteins, the separation and identification of a phosphorylated carbohydrate transport protein intermediate was attempted. Protein IIAGlc (theoretical $M_{\mathrm{r}}=18251$ Da) was phosphorylated in a crude cell extract by the addition of PEP and catalytic quantities of HPr and Enzyme I. (PEP phosphorylates Enzyme I, which transfers its phosphate group to HPr. HPr subsequently transfers its phosphoryl group to Protein IIAGlc). The mixture was then analyzed directly by LC-ESIMS (Figure 3). Figure 3B shows the average mass spectrum corresponding to Peak 1 in the total ion chromatogram. The calculated $M_{\mathrm{r}}$ for this component is $18119 \mathrm{Da}$, which corresponds to Protein IIAGlc minus methionine $(\Delta 131 \mathrm{Da})$. On phosphorylation of Protein IIAGlc, a second major component (Figure 3A, Peak 2) appears in the chromatogram with a molecular weight 80 Da higher than that found for Peak 1 (Figure 3C). This shift represents the replacement mass value of a phosphate group for a tertiary amine or hydroxyl group. Phosphorylation of His-90 of Protein IIAGlc has been reported in the literature (4), and Peak 2 may represent this species. However, any such assignment would need to be verified by peptide mapping of the phosphorylated Protein IIAGlc. This analysis illustrates the power of directly combined LC-MS in providing sample cleanup and initial separation of multiple analytes by reversed-phase chromatography, combined with direct identification and initial structural characterization of the analytes using mass spectrometric detection.

In conclusion, this method should certainly find use for quality control monitoring of protein expression, and in monitoring the chemical modification of specific proteins in response to environmental or metabolic stimuli. Directly combined LC-ESIMS instrumentation has evolved in recent years to the point of being small, affordable and simple to use. The technique described here is therefore immediately accessible not only to the mass spectroscopist or separations scientist but also to anyone interested in the rapid identification and preliminary structural characterization of biomolecules in complex mixtures.

\section{ACKNOWLEDGMENTS}

Certain commercial equipment, instruments and materials are identified in this paper to specify adequately the experimental procedure. Such identification does not imply recommendation or endorsement by the National Institute of Standards and Technology, nor does it imply that the materials or equipment identified are the best available for the purpose.

\section{REFERENCES}

1.Beavis, R.C. and B.T. Chait. 1990. Rapid, sensitive analysis of protein mixtures by mass spectrometry. Proc. Natl. Acad. Sci. USA 87:6873-6877.

2.Cain, T.C., D.M. Lubman and W.J. Weber, Jr. 1994. Differentiation of bacteria using protein profiles from matrix-assisted laser desorption/ionization time-of-flight mass spectrometry. Rapid Commun. Mass Spectrom. 8:10261030.

3.Chong, B.E., D.B. Wall, D.M. Lubman and S.J. Flynn. 1997. Rapid profiling of E. coli proteins up to $500 \mathrm{kDa}$ from whole cell lystates using matrix-assisted laser desorption/ionization time-of-flight mass spectrometry. Rapid Commun. Mass Spectrom. 11:19001908.

4.Dorschug, M., R. Frank, H. R. Kalbitzer, W. Hengstenberg and J. Deutscher. 1984. Phosphoenolpyruvate-dependent phosphorylation site in enzyme IIIglc of the Escherichia coli phosphotransferase system. Eur. J. Biochem. 144:113-119.

5.Easterling, M.L., C.M. Colangelo, R.A. Scott and I.J. Amster. 1998. Monitoring protein expression in whole bacteria cells with MALDI time-of-flight mass spectrometry. Anal. Chem. 70:2704-2709.

6.Fenn, J.B., M. Mann, C.K. Meng, S.F. Wong and C.M. Whitehouse. 1989. Electrospray ionization for mass spectrometry of large biomolecules. Science 246:64-71.

7.Gersten, D.M. 1996. Gel Electrophoresis:Proteins. John Wiley and Sons, New York, NY.

8.Goeddel, D.V. 1990. Methods Enzymol: Vol. 185, Gene Expression Technology. Academic Press, New York, NY.

9.Hung, K.C., H. Ding and B. Guo. 1999. Use of poly(tetrafluoroethylene)s as a sample support for the MALDI-TOF analysis of DNA and proteins. Anal. Chem. 71:518-521.

10.Karas, M., U. Bahr and F. Hillenkamp. 1989. UV laser matrix desorption ionization mass spectrometry of proteins in the 100000 dalton range. Int. J. Mass Spectrom. Ion Processes 92:231-242.

11.Karas, M. and F. Hillenkamp. 1988. Laser desorption ionization of proteins with molecular masses exceeding 10000 daltons. Anal. Chem. 60:2301-2303.

12.Lowry, O.H., N.J. Rosebrough, A.L. Farr and R.J. Randall. 1951. Protein measurement with Folin phenol reagent. J. Biol. Chem. 193:265-275.

13.Rao, R.N. 1984. Construction and properties of plasmid pKC30, a pBR322 derivative containing the PL-N region of phage lambda. Gene 31:247-250.

14.Reddy, P., N. Fredd-Kuldell, E. Liberman and A. Peterkofsky. 1991. Overproduction and rapid purification of the phosphoenolpyruvate:sugar phosphotransferase system proteins Enzyme I, HPr and Protein IIIGlc of Escherichia coli. Protein Exp. Purif. 2:179-187.

15.Reddy, P., A. Peterkofsky and K. McKenney. 1989. Hyperexpression and purification of Escherichia coli adenylate cyclase using a vector designed for expression of lethal gene products. Nucleic Acids Res. 17:10473-10488.

16.Saffen, D.W., K.A. Presper, T.L. Doering and S. Roseman. 1987. Sugar transport by the bacterial phosphotransferase system. Molecular cloning and structural analysis of the Escherichia coli $p t s \mathrm{H}$, ptsI and $c r r$ genes. J. Biol. Chem. 262:16241-16253.

17.Worrall, T.A., R.J. Cotter and A.S. Woods. 1998. Purification of contaminated peptides and proteins on synthetic membrane surfaces for matrix-assisted laser desorption/ionization mass spectrometry. Anal. Chem. 70:750-756.

18.Zuber, M., T.A. Patterson and D.L. Court. 1987. Analysis of nutR, a site required for transcription antitermination in phage lambda. Proc. Natl. Acad. Sci. USA. 84:4514-4518.

Received 21 June 1999; accepted 31 august 1999.

Address correspondence to:

Dr. Joseph J. Dalluge

NIST

100 Bureau Drive

Stop 8392

Gaithersburg, MD 20899-8392, USA

Internet: joseph.dalluge@nist.gov 